\title{
Needs must .....
}

The Education paper on page 773 of this issue addresses a topic that I have referred to in the past and confirms my suspicions about the potential that is being wasted with Continuing Professional Development (CPD). This is a sore point with me, but one so important in its impact on dental education that I feel it is appropriate to look at the topic again. The paper (by Firmstone et al) looks at the impact of course attendance on the practice of dentists - or to put it another way the paper looks at whether attending a postgraduate course has any effect on what happens afterwards. The basic question it tries to answer is - 'Does going on a course make any difference?' The conclusions of the paper are most interesting, but the most telling sentence in the paper comes on page 776, roughly half way down in the first column. The sentence simply states 'None of the 20 showed high impact on practice?

The 20 referred to is the number of case studies carried out as part of the research where 20 dentists who attended courses as part of their CPD were asked afterwards about the effect of the course on their practice. Of these 20 two were ill and so not included, five claimed they learned nothing new, one learnt something new but did nothing about it (for financial reasons relating to NHS fees), four claimed there was a low impact on their practice (for example improved advice to patients), three also claimed low impact but felt they could do more with further training and five made moderate changes to their practice (for example using a new material or technique). When you consider the time, effort and cost of attending a course these results seem pretty depressing.

The problem is that these findings are nothing new. Dentists have been attending postgraduate courses for years (myself among them when I was in practice) and returning to the practice to find the barriers to change prevented any real progress except in exceptional circumstances. I am sure we can all recall the course that stimulated major change in our practice, but this result tends to be the exception. Surely we should do better than that?

Returning to the paper for a moment I was pleased to see the finding that the impact of courses on practice is enhanced when activities are chosen in relation to learning needs. This is hardly surprising, and has been part of management practice used in the commercial world for some time now. Before embarking on paying for training most companies try to identify where there are deficiencies in either competence or confidence for people in doing their jobs - usually referred to as training needs or learning needs. In retrospect this seems so obvious it is hard to understand why we did not do it before, yet Firmstone's paper confirms that few dentists even think of trying to identify their learning needs and then use these as the criteria for course selection. Instead, according to the research, convenience and interest seem more relevant.

And it is here, of course, that the potential for the real value of CPD rests. If all dentists start to grasp the fact that they (along with all the staff in the practice) inevitably have learning needs that help them either carry out their current job now or the job that will develop in the future, then CPD is the ideal way of helping address those needs. For example, negotiating skills is one area where a learning need is almost certain to exist for every dentist intending working within the New Contract in the NHS. We may not know the details of the future yet, but we know the plan is to devolve NHS general practice to the local PCTs, and for the PCTs to develop specific strategies to address local needs. Once this starts to happen then local practitioners may well have a need to negotiate, and it is likely that many of them lack competence in this area. If this is identified as a learning need then CPD can be the mechanism by which this new skill is acquired.

I believe the future for dental practice can be enhanced when practitioners begin to use the management tools that have existed for decades to real effect. Training needs analysis (either via some form of appraisal or as a separate procedure) is a powerful mechanism, and as Firmstone's paper in this issue relates, when a dentist attends a course chosen to help address a learning need then the course is more likely to result in positive and relevant change afterwards.

Mike Grace, Editor

m.grace@bda.org

doi: 10.1038/sj.bdj.4811408 